\title{
Fas/FasL expression in colorectal cancer. An immunohistochemical study
}

\author{
Anna Pryczynicz, Katarzyna Guzińska-Ustymowicz and Andrzej Kemona
}

Department of General Pathomorphology, Medical University of Białystok, Białystok, Poland

\begin{abstract}
The objective of the current study was to assess the expression of Fas ligand (FasL) and Fas receptor (FasR) as the proteins of the post-mitochondrial apoptotic pathway in colorectal carcinoma and to investigate correlations between their expression and chosen clinico-pathological parameters. The protein expression was analyzed in 50 colorectal carcinoma patients, using the immunohistochemical method. Reaction for FasR was weak in $75.5 \%$ and strong in $24.5 \%$ of the study patients, as compared to normal glandular epithelium where FasR expression was strong in $100 \%$ of cases. On the other hand, FasL expression was found to be weak in 30\% and strong in $70 \%$ of colorectal cancer patients, as compared to its lack in $100 \%$ of normal colorectal epithelium. Statistical analysis showed strong expression of FasL was found to correlate statistically significantly with vascular invasion $(\mathrm{p}=0.005)$. No correlations of FasL and FasR expression in the main mass of tumor was found between other clinic-pathological parameters. Fas ligand and Fas receptor appeared to be of little usefulness as prognostic factors for different groups of colorectal carcinoma patients. However, these proteins could become good therapeutic targets for colorectal carcinoma since their expression differs distinctly between normal intestinal epithelium and cancer cells, and known is the mechanism by which cancer cells escape death via apoptosis-inducing Fas/FasL pathway disorders.
\end{abstract}

Key Words: colorectal cancer, Fas, FasL

\section{Introduction}

Apoptosis or suicide-programmed cell death is observed both in physiological and pathological conditions. The process plays an important role in the monitoring of cell count during maturation and functions to remove damaged or cancer cells. Apoptosis is associated with the mitochondria or post-mitochondrial pathway and occurs when cell death signals begin to predominate over the signals that maintain cell life. FasL molecule binding to the specific Fas receptor found on the cell surface is one of the activation signals of the post-mitochondrial pathway [1].

The Fas ligand is a $40-\mathrm{kD}$ type I membrane glycoprotein and a member of the tumor necrosis factor (TNF) family. It can be found on activated $\mathrm{T}$ lymphocytes and NK (natural killer) cells $[2,3]$. The Fas protein is a specific receptor for FasL (also called CD95 or APO-1) and a 40-kD type II membrane glycoprotein homologous to

Correspondence: K. Guzińska-Ustymowicz, Dept. of General Pathomorphology, Medical University of Białystok, Waszyngtona Str. 13, 15-269 Bialystok, Poland; tel.: (+4885) 7485942, fax.: (+4885) 7485996, e-mail: kasia.guzinska@gmail.com
TNF. This protein occurs on various types of normal cells, e.g.: in the thymus, lungs, intestines, spleen, prostate or uterus $[2,4]$. The Fas receptor upon binding to the FasL activates its death domain (DD) and thus triggers a series of caspases [3,6-8], which results in cells death. The Fas system is responsible for cytotoxic T cellmediated apoptosis and plays a major role in the maintenance of immunological homeostasis [5]. This process is impaired in neoplastic disease as cancer cells prevent apoptosis. The involvement of these proteins has been described in such malignancies as tumors of the breast [6], lungs [7], esophagus [8] or stomach [9].

Due to the fact that colorectal carcinoma is one of the most common malignancies both in women and men, especially those over 50 years of age, the objective of the current study was to assess the expression of FasL and FasR in colorectal carcinoma, and to investigate the relationship between their expression and chosen clinicopathological parameters.

\section{Materials and methods}

Tissue samples. The study group consisted of 50 patients with colorectal carcinoma, operated on in the Surgical Department of the J. Sniadecki Hospital in Bialystok. Colorectal carcinoma specimens 
and 17 control samples of normal colorectal mucosa were examined. Sections, $4 \mu \mathrm{m}$-thick, were cut from paraffin blocks and stained with hematoxylin and eosin $(\mathrm{H}+\mathrm{E})$. The routine histopathological assessment of the sections referred to the histological type, malignancy grade $(\mathrm{G})$, clinico-pathological pTN status, regional lymph node involvement, presence of distant metastases, lymphocytic infiltration, vascular invasion and tumor budding. Inflammatory lymphocytic infiltration was graded as: 0 - lack, 1 - weak, diffused, 2 - moderate, 3 - strong, lymphocyte nests according to the Jass classification [10]. Lymphatic and venous invasions were examined, and assessed together as vascular invasion as in Guzinska-Ustymowicz article [11]

Immunohistochemical analysis. Formalin-fixed and paraffinembedded tissue specimens were cut on a microtome into $4 \mu \mathrm{m} \mathrm{sec}-$ tions. The sections were deparaffinized in xylenes and hydrated in alcohols. To visualize the antigen, the sections were heated in a microwave oven for $15 \mathrm{~min}$ in a citrate buffer $(\mathrm{pH} \mathrm{6.0)}$. They were incubated with $3 \%$ hydrogen peroxide solution in order to block endogenous peroxidase. Next, incubation was performed with mouse monoclonal antibody against human Fas (Sc-8009, Santa Cruz Biotechnology) over the night at $4{ }^{\circ} \mathrm{C}$ and with goat polyclonal antibody against human FasL (Sc-834-G, Santa Cruz Biotechnology). The reaction was carried out using biotinylated anti-mouse antibody and streptavidin-conjugated with horseradish peroxidase (LSAB2, DAKO, Poland). A colour reaction for peroxidase was developed with chromogene DAB (DAKO, Poland). Fas and FasL expressions were determined using the semiquantitative method and assessed as strong (reaction visible in $\geq 25 \%$ of tumour cells) and weak (lack of reaction or the reaction present in $<25 \%$ of cancer cells). Positive reactions were calculated in at least 500 cancer cells in each tissue specimen under a light microscope $(\times 400)$.

Statistical analysis. Statistical analysis was conducted using Spearman's correlation coefficient test. A p-value of $<0.05$ was considered statistically significant. Missing data were removed in pairs.

\section{Results}

\section{Fas and FasL expression in normal mucosa and colorectal adenocarcinoma}

The expression of Fas receptor was observed on the cell membrane whereas FasL was present in the cytoplasm of the glandular epithelial cells in the control samples and in the colorectal carcinoma cells (Fig. 1). Among the 50 patients with colorectal carcinoma, the histochemical reaction for FasR was found to be weak in $75.5 \%$ and strong in $24.5 \%$ of cases. In the control group, with normal glandular epithelium, the expression of Fas was strong in $100 \%$ of cases. However, the expression of FasL in colorectal cancer patients was found to be weak in $30 \%$ and strong in $70 \%$ of the study cases, but absent in the control group (Fig. 2). Moreover, over $50 \%$ of the lymphocytes present in the inflammatory infiltration accompanying the tumor showed strong FasR expression (Fig. 3).

\section{Relationship between Fas and clinico- -pathological parameters}

Statistical analysis showed no correlations of Fas protein expression in the main mass of tumor with patients' age, gender, tumor location, histological type, pT stage, lymph node involvement, presence of distant metastases, inflammatory lymphocytic infiltration, vascular invasion or tumor budding (Table 1).

\section{Relationship between FasL and clinico-patho- logical parameters.}

No correlation was also noted of FasL expression with patients' age or gender, tumor location, histological type, pT stage, lymph node involvement, presence of distant metastases, inflammatory lymphocytic infiltration or tumor budding. However, the strong FasL expression was observed to correlate statistically significantly with the presence of vascular invasion $(\mathrm{p}=0.005)$ (Table 1).

\section{Discussion}

Apoptosis is an extremely important phenomenon in the development and life of organisms, ensuring removal of unnecessary and even potentially dangerous cells, with impaired genetic (DNA) information. However, cancer cells escape the mechanism and tend to proliferate in an uncontrolled way. We observed a marked increase in FasL protein expression and a drop in Fas receptor in colorectal cancer cells as compared to normal glandular cells in the colon. These observations seem to be consistent with the findings reported by other authors. Belluco et al [12] presented the results in which FasL expression showed a linear correlation with cancer progression from hyperplastic polyps to advanced colorectal carcinoma (pT4). Zhu et al. [13] also observed high FasL expression in $84.9 \%$ of colorectal cancers as compared to normal glandular epithelium (3.75\%), and lower Fas receptor expression in $43.4 \%$ of colorectal cancer cases than in normal epithelium (73.3\%). Thus, low expression of Fas receptor in cancer cells may suggest that the Fas/FasL pathway inducing apoptosis in these cells was reduced or eliminated.

Moreover, we observed Fas/FasL positive lymphocytes. Their presence in the vicinity of neoplastic infiltration and the presence of high FasL expression in cancer cells seem to reflect the defense mechanism of cancer cells against anticancer immune cells. This was suggested by Okada [14] and Zhu [13], who investigated apoptosis in tumor-infiltrating lymphocytes (TILs). They demonstrated that apoptosis in TILs increased with higher expression of FasL protein in colorectal cancer cells. Thus, cancer cells produce Fas ligand in the defense against Fas-positive lymphocytes by inducing apoptosis in them. In this way, they defend themselves against the immune response of the organism and therefore escape death that would come from the immune cells. This defense mechanism of cancer cells allows tumor growth in local tissue or even in distant organs. 

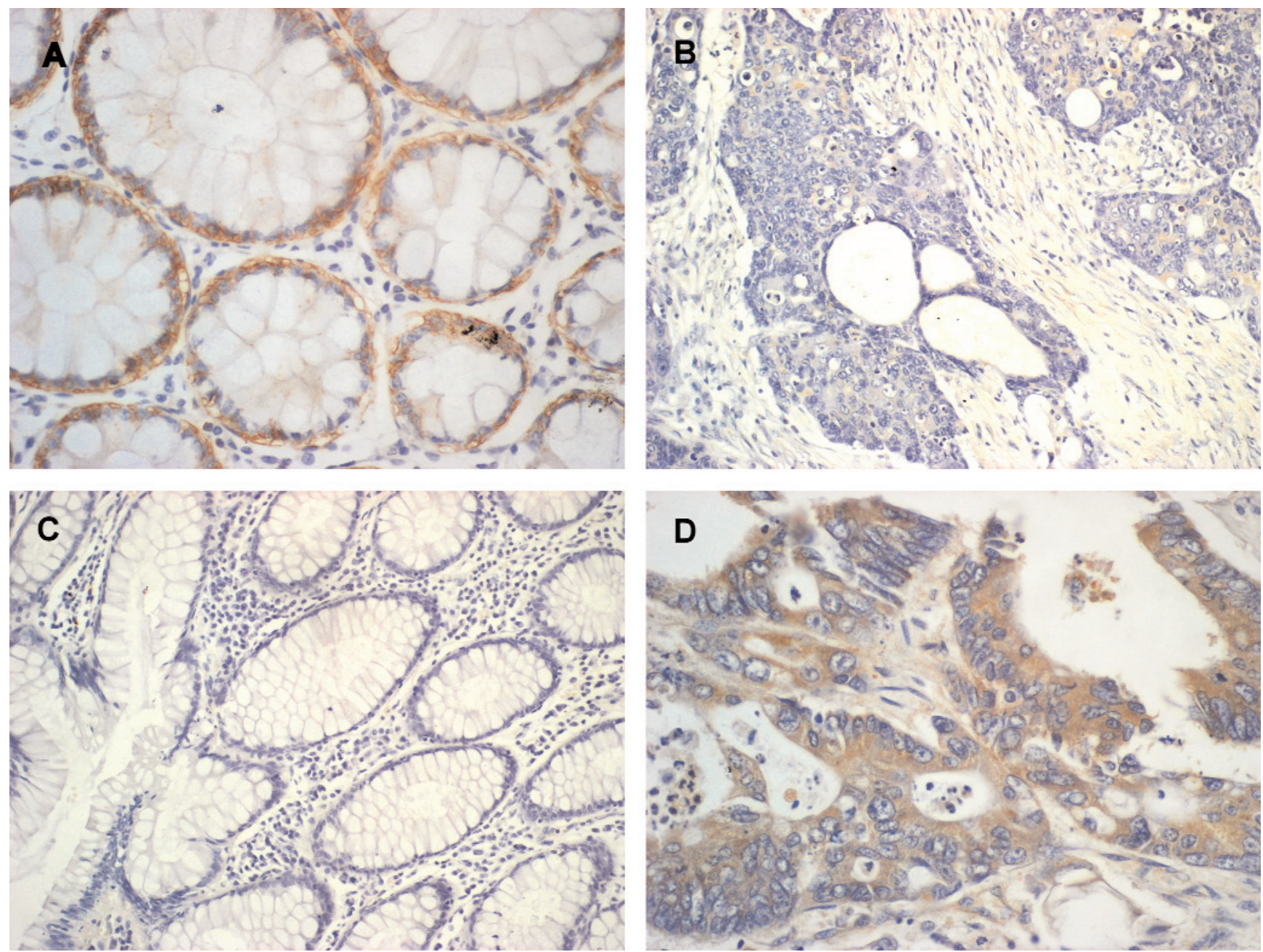

Fig. 1. Immunohistochemical staining. Cytoplasmic Fas receptor expression in normal mucosa (A) and colorectal cancer (B) and FasL protein expression in normal mucosa (C) and colorectal cancer (D) (original magnification $\times 400$ ).

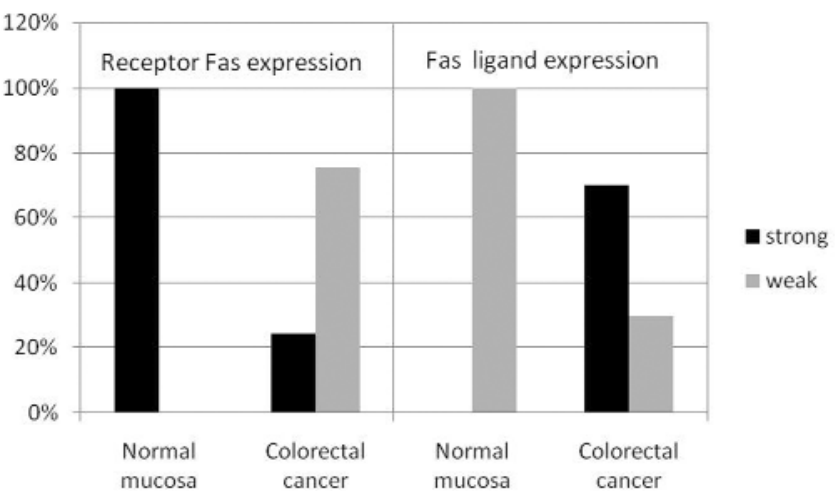

Fig. 2. Patterns of Fas and FasL expression in 17 normal mucosa specimens and 50 colorectal adenocarcinomas.

Since significant changes have been demonstrated in the expressions of Fas and FasL proteins and their role in the defense of cancer cells has been considered, we could expect them to play a major part in patients' prognosis. However, in our study the expressions of

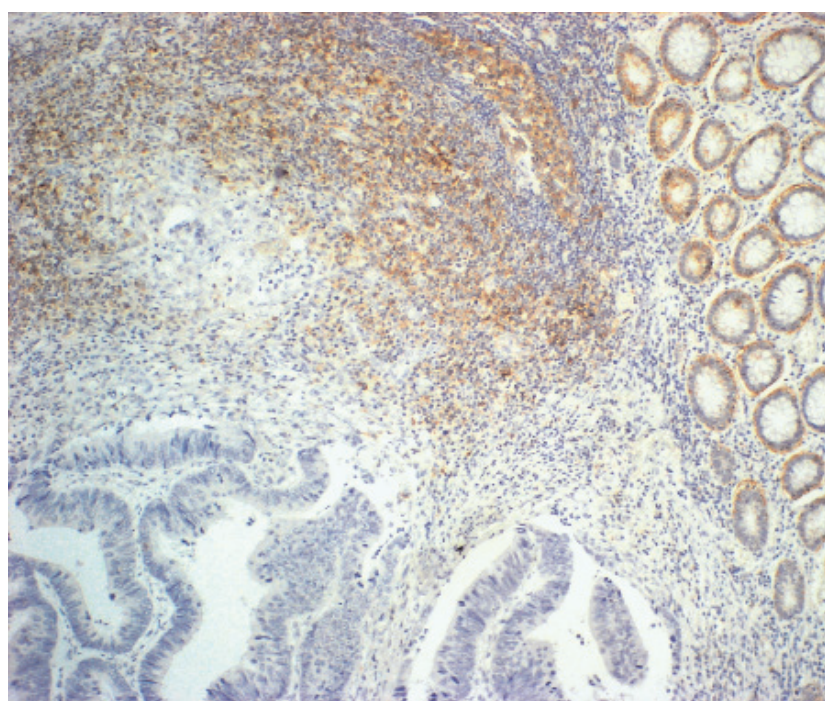

Fig. 3. Strong Fas receptor expression visible in normal glandular epithelium of the colon and in grade 3 lymphatic infiltration. Lack of reaction in cancer cells of the colon (original magnification $\times 400)$. 
Table 1. Relationship between Fas and FasL expression in primary lesion of colorectal cancer and clinicopathological factors. Relationship is significant at the level of $\mathrm{p}<0.05$. Significant relationship is marked in bold.

\begin{tabular}{|c|c|c|c|c|c|c|c|}
\hline \multirow{2}{*}{\multicolumn{2}{|c|}{ Variables }} & \multicolumn{2}{|c|}{ Fas expression } & \multirow{3}{*}{$\begin{array}{c}\text { p value } \\
0.377\end{array}$} & \multicolumn{2}{|c|}{ FasL expression } & \multirow{3}{*}{$\begin{array}{c}\mathrm{p} \text { value } \\
1.000\end{array}$} \\
\hline & & \multirow{2}{*}{$\begin{array}{c}\text { weak } \\
8(88.9 \%)\end{array}$} & \multirow{2}{*}{$\frac{\text { strong }}{1(11.1 \%)}$} & & \multirow{2}{*}{$\frac{\text { weak }}{3(30 \%)}$} & \multirow{2}{*}{$\frac{\text { strong }}{7(70 \%)}$} & \\
\hline & $\leq 60$ & & & & & & \\
\hline Age & $>60$ & $30(75 \%)$ & $10(25 \%)$ & & $12(30 \%)$ & $28(70 \%)$ & \\
\hline \multirow{2}{*}{ Gender } & Male & $16(66.7 \%)$ & $8(33.3 \%)$ & 0.076 & $6(26.1 \%)$ & $17(73.9 \%)$ & 0.586 \\
\hline & Female & $22(88 \%)$ & $3(12 \%)$ & & $9(33.3 \%)$ & $18(66.7 \%)$ & \\
\hline \multirow{2}{*}{ Localization } & Colon & $21(70 \%)$ & $9(30 \%)$ & 0.116 & $8(26.7 \%)$ & $22(73.3 \%)$ & 0.538 \\
\hline & Rectum & $17(89.5 \%)$ & $2(10.5 \%)$ & & $7(35 \%)$ & $13(65 \%)$ & \\
\hline \multirow{2}{*}{ Adenocarcinoma type } & Nonmucinous & $35(81.4 \%)$ & $8(18.6 \%)$ & 0.087 & $15(34.1 \%)$ & $29(65.9 \%)$ & 0.090 \\
\hline & Mucinous & $3(50 \%)$ & $3(50 \%)$ & & $0(0 \%)$ & $6(100 \%)$ & \\
\hline \multirow{2}{*}{ pT stage } & 2 & $3(100 \%)$ & $0(0 \%)$ & 0.346 & $1(33.3 \%)$ & $2(66.7 \%)$ & 0.899 \\
\hline & 3 & $35(76 \%)$ & $11(24 \%)$ & & $14(29.8 \%)$ & $33(70.2 \%)$ & \\
\hline \multirow{2}{*}{$\begin{array}{l}\text { Lymph node } \\
\text { metastasis }\end{array}$} & Absent & $23(85.2 \%)$ & $4(14.8 \%)$ & 0.162 & $11(39.3 \%)$ & $17(60.7 \%)$ & 0.110 \\
\hline & Present & $15(68.2 \%)$ & $7(31.8 \%)$ & & $4(18.2 \%)$ & $18(81.8 \%)$ & \\
\hline \multirow{2}{*}{ Distant metastasis } & Absent & $34(79 \%)$ & $9(21 \%)$ & 0.505 & $13(29.5 \%)$ & $31(70.5 \%)$ & 0.853 \\
\hline & Present & $4(66.7 \%)$ & $2(33.3 \%)$ & & $2(33.3 \%)$ & $4(66.7 \%)$ & \\
\hline \multirow{4}{*}{$\begin{array}{l}\text { Lymphocytic } \\
\text { infiltration }\end{array}$} & 0 & $3(60 \%)$ & $2(40 \%)$ & 0.688 & $2(33.3 \%)$ & $4(66.7 \%)$ & 0.900 \\
\hline & 1 & $20(80 \%)$ & $5(20 \%)$ & & $7(28 \%)$ & $18(72 \%)$ & \\
\hline & 2 & $13(81.2 \%)$ & $3(18.8 \%)$ & & $6(37.5 \%)$ & $10(62.5 \%)$ & \\
\hline & 3 & $2(66.7 \%)$ & $1(33.3 \%)$ & & $0(0 \%)$ & $3(100 \%)$ & \\
\hline \multirow{2}{*}{ Vascular invasion } & 0 & $18(81.8 \%)$ & $4(18.2 \%)$ & 0.528 & $11(50 \%)$ & $11(50 \%)$ & 0.005 \\
\hline & 1 & $20(74.1 \%)$ & $7(25.9 \%)$ & & $4(14.3 \%)$ & $24(85.7 \%)$ & \\
\hline \multirow{2}{*}{ Tumor budding } & Absent & $8(80 \%)$ & $2(20 \%)$ & 0.943 & $4(40 \%)$ & $6(60 \%)$ & 0.380 \\
\hline & Present & $30(79 \%)$ & $8(21 \%)$ & & $10(25.6 \%)$ & $29(74.4 \%)$ & \\
\hline
\end{tabular}

Fas and FasL proteins showed no correlation with any of the important clinicopathological parameters, such as histological type, $\mathrm{pT}$ stage or the presence of local lymph node involvement or distant metastases. Other researchers observed a correlation between FasL overproduction and metastasizing. Okada et al. [14] noted that FasL protein expression may be associated with local lymph node involvement. Moreover, Zhang et al. [15] observed positive expression of FasL protein in all metastases of colorectal carcinoma to the liver; FasL was found to correlate statistically significantly with metastases to the liver and lymph nodes. Yokomizo et al. [16] revealed that FasL protein expression can serve as a prognostic factor for metastases to the liver in colorectal carcinomas with vascular invasion. Likewise, in our study, the occurrence of cancer embolism in blood and lymphatic vessels appeared to be statistically significant in patients with strong expression of FasL protein ( $85.6 \%$ of cases), whereas low expression was present only in $14.3 \%$ of patients. This may indicate FasL protein involvement in cancer progression. Nozoe et al. [17] not only observed FasL correlation with metastases to lymph nodes and distant organs, but also with Dukes' classification, superficial tumor type, depth of infiltration and lymphatic permeation of the colorectal carcinoma, but not with vascular invasion. In other studies, the expression of FasL protein was found to correlate with histological type [18,19], high level of microsatellite instability (MSI-H) $[18,20]$ and patients' survival [19].

Similarly to our studies, many authors also found no correlations between the respective clinicohistopathological parameters, such as histological differentiation grade [14,15,18-21], Dukes' classification $[14,20]$, tumor histological type [20] and location $[14,17,19,20]$, depth of infiltration [15] and the presence of local lymph node involvement or distant metastases [19]. It would be interesting to consider whether the changes in FasL protein and Fas receptor expression would be useful prognostic factors for colorectal carcinoma patients. Different researchers show divergent results for the correlation between the protein expression and clinicopathological parameters of the tumor. Undoubtedly, however, these proteins could 
become good therapeutic targets in colorectal carcinoma since their expression differs distinctly between normal intestinal epithelium and cancer cells, and known is the mechanism by which cancer cells escape death due to the apoptosis-inducing Fas/FasL pathway disorders.

\section{References}

[1] Carson DA, Ribeiro JM. Apoptosis and disease. Lancet. 1993;341:1251-1254.

[2] Nagata S, Golstein P: The Fas death factor. Science. 1995;267:1449-56.

[3] Suda T, Takahashi T, Golstein P, Nagata S. Molecular cloning and expression of the Fas ligand, a novel member of the tumor necrosis factor family. Cell. 1993;75:1169-1178.

[ 4] Leithauser F, Dhein J, Mechtersheimer G, et al. Constitutive and induced expression of APO-1 a new member of the nerve growth fator/tumor necrosis factor receptor superfamily, in normal and neoplastic cells. Lab Invest. 1993;69:415-429.

[5] Lee RK, Spielman J, Zhao DY, Olsen KJ, Podack ER. Perforin, Fas ligand, and tumour necrosis factor are the major cytotoxic molecules used by lymphokine-activated killer cells. J Immunol. 1996;157:1919-1925.

[6] Bębenek M, Duś D, Koźlak J. Fas expression in primary breast cancer is related to neoplastic infiltration of perilymphatic fat. Adv Med Sci. 2008;53:49-53.

[7] Niehans GA, Brunner T, Grizelle SP, et al. Human lung neoplasms express Fas ligand. Cancer Res. 1997;57:1007-1012.

[ 8] Shibakita M, Tachibana M, Dhar DK, et al. Prognostic significance of Fas and Fas ligand expressions in human esophageal cancer. Clin Cancer Res. 1999;5:2464-9246.

[ 9] Nagashima H, Mori M, Sadanaga N, Mashino K, Yoshikawa Y, Sugimachi K. Expression of Fas ligand in gastric carcinoma relates to lymph node metastasis. Int $J$ Oncol. 2001;18:1157-1162.

[10] Jass JR. Lymphocytic infiltration and survival in rectal cancer. J Clin Pathol. 1986;39:585-589.

[11] Guzińska-Ustymowicz K. Aggressive and non-aggressive tumor budding in colorectal cancers. In: Tumor budding in colorectal cancer (Muto T, Mochizuki H, Masaki T (eds.). Nova Science Publisher, pp 105-116, 2006.

[12] Belluco C, Esposito G, Bertorelle R, et al. Fas ligand is upregulated during the colorectal adenoma-carcinoma sequence. Eur J Surg Oncol. 2002;28:120-125.

[13] Zhu Q, Liu JY, Xu HW, et al. Mechanism of counterattack of colorectal cancer cell by Fas/Fas ligand system. World J Gastroenterol. 2005;11:6125-6129.

[14] Okada K, Komuta K, Hashimoto S, Matsuzaki S, Kanematsu T, Koji T. Frequency of apoptosis of tumor-infiltrating lymphocytes induced by fas counterattack in human colorectal carcinoma and its correlation with prognosis. Clin Cancer Res. 2000;6:3560-3564.

[15] Zhang W, Ding EX, Wang Q, et al. Fas ligand expression in colon cancer: a possible mechanism of tumor immune privilege. World J Gastroenterol. 2005;11:3632-3635.

[16] Yokomizo H, Yoshimatsu K, Ishibashi K, et al. Fas ligand expression is a risk factor for liver metastasis in colorectal cancer with venous invasion. Anticancer Res. 2003;23:52215224.

[17] Nozoe T, Yasuda M, Honda M, Inutsuka S, Korenaga D. Fas ligand expression is correlated with metastasis in colorectal carcinoma. Oncology. 2003;65:83-88.

[18] Michael-Robinson JM, Pandeya N, Cummings MC, et al. Fas ligand and tumour counter-attack in colorectal cancer stratified according to microsatellite instability status. $J$ Pathol. 2003;201:46-54.

[19] Sheehan KM, O'Donovan DG, Fitzmaurice G, et al. Prognostic relevance of Fas (APO-1/CD95) ligand in human colorectal cancer. Eur J Gastroenterol Hepatol. 2003;15:375-380.

[20] Houston AM, Michael-Robinson JM, Walsh MD, et al. The "Fas counterattack" is not an active mode of tumor immune evasion in colorectal cancer with high-level microsatellite instability. Hum Pathol. 2008;39:243-250.

[21] O'Connell J, Bennett MW, O'Sullivan GC, et al. Fas ligand expression in primary colon adenocarcinomas: evidence that the Fas counterattack is a prevalent mechanism of immune evasion in human colon cancer. J Pathol. 1998;186:240-246.

Submitted: 23 April, 2010 Accepted after reviews: 11 July, 2010 